http://jmscr.igmpublication.org/home/ ISSN (e)-2347-176x ISSN (p) 2455-0450 crossref DOI: https://dx.doi.org/10.18535/jmscr/v9i5.08

\author{
Journal Of Medical Science And Clinical Research \\ IGM Publication \\ An Official Publication of IGM Publication
}

\title{
An Atypical Case of Primary Sjogren's Syndrome Presenting as Chronic Inflammatory Demyelinating Polyradiculoneuropathy
}

\author{
Authors
}

\section{Dr Uttayan Chakrabarti1, Dr Cankatika Choudhury2, Dr Vinod Chaitanya 3 , Dr Geetika Khanna 4}

\begin{abstract}
${ }^{1}$ Senior Resident, Department of Nephrology, Vardhman Mahavir Medical College and Safdarjung Hospital ${ }^{2}$ DM Neurology trainee, Department of Neurology, Vardhman Mahavir Medical College and Safdarjung Hospital

${ }^{3}$ Associate Professor, Department of Medicine, Vardhman Mahavir Medical College and Safdarjung Hospital

${ }^{4}$ Professor, Department of Pathology, Vardhman Mahavir Medical College and Safdarjung Hospital

*Corresponding Author

Dr Cankatika Choudhury, MBBS,MD (Medicine)
\end{abstract}

DM Neurology trainee, Department of Neurology,Vardhman Mahavir Medical College and Safdarjung Hospital

\begin{abstract}
Sjogren's Syndrome is a chronic autoimmune disorder affecting exocrine glands. During the course of illness, there is multi system involvement. Neurological manifestations may occur in 8.5-70\% of diagnosed cases. It is well established that primary Sjogren's Syndrome is associated with peripheral neuropathy to the tune of 10-20\% although CNS involvement is much less common. These neuropathies are typically sensory or autonomic. The varieties can range from mononeuritis multiplex, distal sensory neuropathy, painful small fibre neuropathy to sensory neuronopathy. Herein, we describe an uncommon case of Sjogren's syndrome presenting with Chronic Inflammatory Demyelinating Polyradiculoneuropathy. The former denied the hallmark sicca symptoms and was discovered on further immunological studies.
\end{abstract}

Keywords: Autoimmune disorder,Peripheral neuropathy, Sicca symptoms.

\section{Introduction}

Primary Sjogren's Syndrome is a chronic autoimmune disorder with damage to the exocrine glands and multisystem involvement ${ }^{[1]}$. The earliest reports of neurological involvement dates back to the 1980 s with a prevalence estimate of $8.5-70 \%{ }^{[2,3]}$. Interestingly, neurological symptoms preceded the diagnosis of pSS by 2 years and in the remaining the symptoms appeared about 6-8 years of diagnosis. Mostly, the peripheral nervous system is involved and it is a negative prognostic factor as it increases the risk of Non-Hodgkin's Lymphoma $^{[4]}$. The gamut ranges from mononeuritis multiplex, distal sensory neuropathy, painful small fibre neuropathy to sensory neuronopathy ${ }^{[5,6]}$. Motor predominant neuropathies mimicking Guillain Barre Syndrome and Chronic Inflammatory Demyelinating Polyradiculoneuropathy are now being seen and could be the presenting symptom with improvement on Intravenous Immune Globulin therapy ${ }^{[7,8,9]}$. The knowledge regarding CNS involvement is not well structured but the following can be seen: aseptic meningitis, optic neuritis, multiple -sclerosis like manifestations, acute transverse myelitis \& cognitive disorders 
[10]. Reports of Amyotrophic Lateral Sclerosis associated with Sjogren's Syndrome have also surfaced.

\section{Case Report}

21-year-old post-partum female presented to the Out Patient Department with subacute onset progressive distal followed by proximal weakness of both lower limbs, right followed by left for 3 months. She also complained of difficulty in gripping objects for the past 15 days. Earlier, she was able to walk with support of two persons but after her delivery about 2 weeks back, her weakness deteriorated to the extent that she became bed bound \& required help for the activities of daily living. There were also pins and needles sensation below the knees for the same duration. There were no sensory level, cranial nerve, bladder bowel involvement,no preceding history of fever, sore throat, loose stools or rashes and no similar events in the past.

On examination, she was conscious and her vitals were stable. Cranial nerves were intact. The tone was reduced in all four limbs. The power was MRC Grade 1/5 in all muscle groups in both lower limbs and MRC Grade 3/5 in both upper limbs. All the deep tendon reflexes were diminished and plantar was bilateral flexor. Joint position sense was impaired at the great toe \& ankle. Vibration sense was impaired at the right up to the tibial shin and the anterior superior iliac spine in the left.

Her labs showed Hb-11.8 g/dl, MCV-94 fl, MCHC-33g/dl, Plt-1,58,000 / cu. mm, TLC-6,500 / cu. mm(N-68.2,L-28.8),Na/K- 136/4.2 meq/l , Urea/Creatinine-15/0.3mg/dl ,Total Bilirubin$0.8 \mathrm{mg} / \mathrm{dl}$,AST/ALT/ALP-21/13/75 IU, Total protein-7.1g/dl,Albumin-3.5 g/dl.

$\mathrm{NCV}$ was done on day 4 of admission. The motor nerve conduction findings revealed non recordable potentials in bilateral common peroneal and posterior tibial nerves, increased distal latencies and reduced $\mathrm{CV}$ in bilateral median and ulnar nerves, reduced CMAP in left ulnar nerve, conduction block in bilateral median and left ulnar nerves. Sensory nerve conduction findings revealed reduced $\mathrm{CV}$ in bilateral median and ulnar nerves, non- recordable potentials in bilateral sural nerves. $\mathrm{F}$ waves were prolonged in bilateral median and ulnar nerves. Findings were suggestive of distal symmetrical generalised primary demyelinating with axonal polyneuropathy [Figure 1]. The electrodiagnostic findings fulfilled the criteria of Inflammatory Neuropathy Cause and Treatment (INCAT) for the diagnosis of CIDP.

Lumbar puncture was done and the CSF revealed 10 cells (L-52\%, P-48\%), protein-525.4mg/ dl, Sugar-76mg/dl, ADA-6 which was suggestive of an albumin-cytological dissociation. A diagnosis of Chronic Inflammatory Demyelinating Polyradiculoneuropathy was made based on the European Federation of Neurological Society Criteria 2010 ${ }^{[11]}$.

On day 6 , she was started on IVIg at $2 \mathrm{~g} / \mathrm{kg}$ body weight given over 5 days followed by oral Prednisolone $50 \mathrm{mg}$ at $1 \mathrm{mg} / \mathrm{kg}$ body weight daily. Patient responded to treatment with gradual improvement in power of the limbs (MRC grade 4-/5) with appearance of the vibration sense over the lower limbs, deep tendon reflexes in the upper limbs after two weeks. The paraesthesia of a lower intensity persisted.

She was investigated further to rule out any primary cause of CIDP and her serology was nonreactive, ANA was positive (3+ on IF) with a homogenous pattern, ENA profile revealed anti SS-A antibodies being strongly positive, positive RO-52 antibodies and a borderline positive U1 $\mathrm{SM} / \mathrm{RNP}$ antibodies. Schirmer's test revealed $>5 \mathrm{~mm}$ wetting in 5 minutes. Lip biopsy was performed and showed irregular mucosal \& mild peri appendageal chronic inflammation \& unremarkable minor salivary glands. The finding though not pathognomonic of Sjogrens but the subdued inflammatory finding was probably due to the effect of steroids as consulted with the pathologist.[Figure 2]. Other laboratory data including hepatitis B surface antigen, antihepatitis C virus, HIV I \& II, 
Immunoelectrophoresis and Rheumatoid factor were all negative. This pointed to a diagnosis of Primary Sjogren's and the CIDP was a presenting feature of the former. Patient was discharged on maintenance dose oral steroids and kept in regular follow up.

Figure 1: Motor nerve conduction study

\begin{tabular}{|c|c|c|c|c|c|c|c|c|c|c|}
\hline NERVE & $\begin{array}{l}\text { LATENCY(ms) } \\
\text { D }\end{array}$ & $\begin{array}{l}\text { LATENCY (ms) } \\
\text { P }\end{array}$ & $\begin{array}{l}\text { AMPUTUDE } \\
\text { (Mv) } \\
\text { D }\end{array}$ & $\begin{array}{l}\text { AMPUTUDE } \\
(\mathrm{Mv}) \\
\mathrm{p}\end{array}$ & \%dec & $\begin{array}{l}\text { DURAT } \\
\text { ON } \\
\text { D }\end{array}$ & $\mathbf{P}$ & $\%$ inct & $\begin{array}{l}\mathrm{CV} \\
(\mathrm{m} / \mathrm{s})\end{array}$ & $F-\operatorname{Min}(m / s)$ \\
\hline RT.MEDIAN & 13 & 25.75 & 9.53 & 3.33 & 65.06 & 25,50 & 24.50 & 210 & 16.47 & 49.75 \\
\hline RT.ULNAR & 7.37 & 16.12 & 5.77 & 3.31 & 42.63 & 31 & 31.12 & 210 & 26.29 & 46 \\
\hline LT.MEDIAN & 9.62 & 15.75 & 10.52 & 4.34 & 58.75 & 26.67 & 29.50 & 210 & 34.26 & 52.87 \\
\hline LT. ULNAR & 7.25 & 15.75 & 4.19 & 1.84 & 56.09 & 25.62 & 33.0 & 210 & 27.06 & 50 \\
\hline
\end{tabular}

Sensory nerve conduction study

\begin{tabular}{|l|l|l|l|l|}
\hline NERVE & LATENCY(ms) & AMPLTUDE (Uv) & DISTANCE (mm) & CV( $\mathrm{m} / \mathrm{s})$ \\
\hline RT.SURAL & & & & \\
\hline LT.SURAL & & & 120 & 34.78 \\
\hline RT.MEDIAN & 3.45 & 15.14 & 120 & 28.85 \\
\hline LT.MEDIAN & 4.16 & 10.29 & 90 & 28.94 \\
\hline RT.ULNAR & 3.11 & 11.01 & 90 & 27.86 \\
\hline LT.ULNAR & 3.23 & 14.10 & 90 & \\
\hline
\end{tabular}

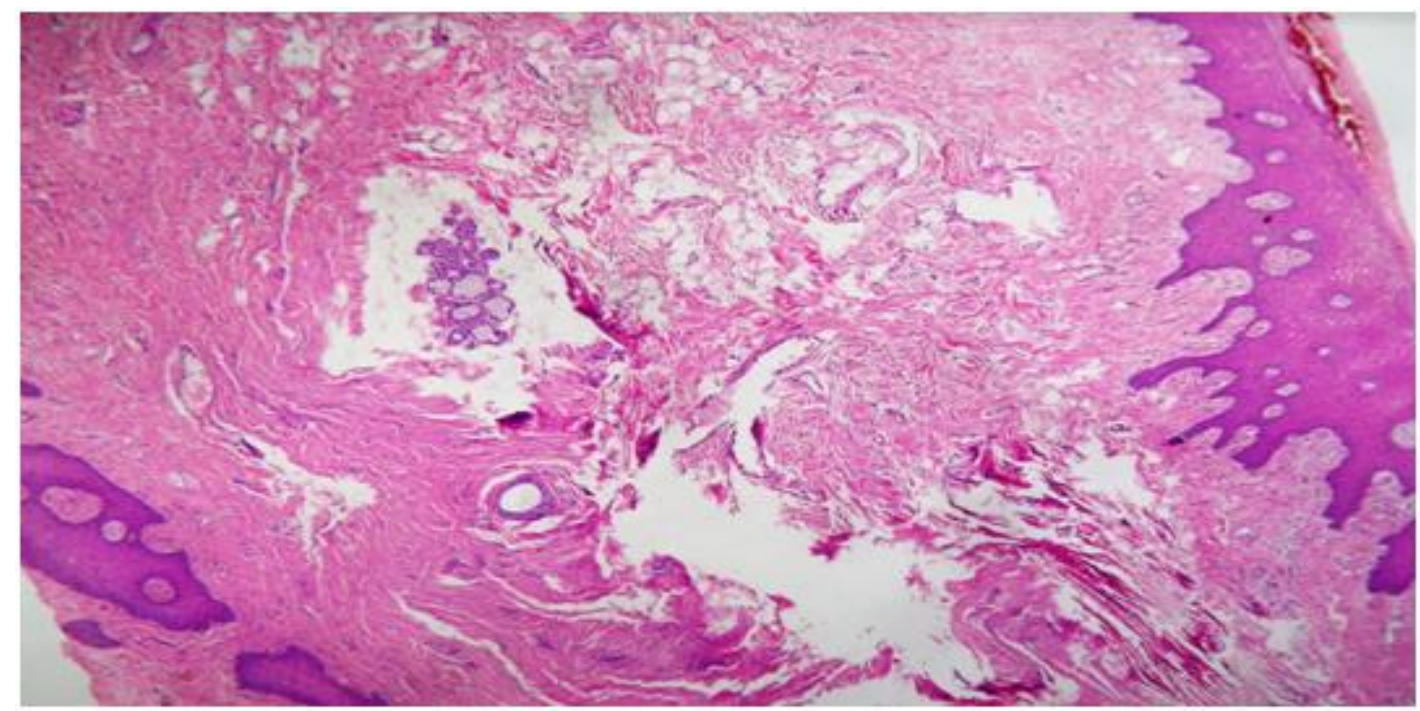

Figure 2: biopsy from lower lip showing irregular mucosal \& mild peri appendageal chronic inflammation $\&$ unremarkable minor salivary glands 


\section{Discussion}

To our knowledge, this is the first case of Primary Sjogren's syndrome presenting with CIDP without any sicca symptoms clinically. What is remarkable is the course of evolution of symptoms in the disease process of Sjogren's Syndrome with extra glandular involvement antedating glandular involvement. Furthermore, there was worsening of symptoms in the postpartum period. The patient improved with IVIG and showed signs of motor recovery within two weeks. Hence, the patient could be educated about the symptoms which could ensue and about early reporting of the same.

CIDP can be thought of as window to an underlying disorder. There is limited data on CIDP in Sjogren's Syndrome ${ }^{[12,13]}$. Both are thought as separate processes and not one as a manifestation of the other. CIDP \& Sjogren's Syndrome may share the same underlying pathogenesis including vasculitis and humoraland/or cellular-mediated immune responses. The important take home message is that any CIDP should be investigated thoroughly for underlying autoimmune disorders \& early treatment can cause marked improvement of symptoms as in our case $^{[14,15]}$. Neurological manifestations in absence of sicca symptoms often result in delayed diagnosis of Primary Sjogren's.A positive immunological test leads to an early diagnosis of Primary Sjogren's syndrome several years before the onset of typical sicca symptoms and timely institution of treatment would help prevent the systemic complications like chronic organ damage, lymphoma ${ }^{[16]}$.

\section{Conflict of Interests}

The authors declare no conflict of interests.

\section{References}

1. Both T, Dalm VA, van Hagen PM, van Daele PL. Reviewing primary Sjögren's syndrome: beyond the dryness-from pathophysiology to diagnosis and treatment. International journal of medical sciences. 2017;14(3):191.

2 Chai J, Logigian EL. Neurological manifestations of primary Sjogren's syndrome. Current opinion in neurology. 2010 Oct 1;23(5):509-13.

3. Lafitte C. Neurological manifestations in Sjögren syndrome. Archives of neurology. 2000 Mar 1;57(3):411-3.

4. Delalande S, De Seze J, Fauchais AL, Hachulla E, Stojkovic T, Ferriby D, Dubucquoi S, Pruvo JP, Vermersch P, Hatron PY. Neurologic manifestations in primary Sjögren syndrome: a study of 82 patients. Medicine. 2004 Sep 1;83(5):28091.

5. Gøransson LG, Herigstad A, Tjensvoll AB, Harboe E, Mellgren SI, Omdal R. Peripheral neuropathy in primary Sjögren syndrome: a population-based study. Archives of Neurology. 2006 Nov 1;63(11):1612-5.

6. Sène $D$, Jallouli $M$, Lefaucheur JP, Saadoun D, Costedoat-Chalumeau N, Maisonobe T, Diemert MC, Musset L, Haroche J, Piette JC, Amoura Z. Peripheral neuropathies associated with primary Sjögren syndrome: immunologic profiles of nonataxic sensory neuropathy and sensorimotor neuropathy. Medicine. 2011 Mar 1;90(2):133-8.

7. Pavlakis PP, Alexopoulos $\mathrm{H}$, Kosmidis ML, Stamboulis E, Routsias JG, Tzartos SJ, Tzioufas AG, Moutsopoulos HM, Dalakas MC. Peripheral neuropathies in Sjögren syndrome: a new reappraisal. Journal of Neurology, Neurosurgery \& Psychiatry. 2011 Jul 1;82(7):798-802.

8. Awad A, Mathew S, Katirji B. Acute motor axonal neuropathy in association with Sjögren syndrome. Muscle \& nerve. 2010 Nov;42(5):828-30.

9. Sivadasan A, Muthusamy K, Patel B, Benjamin RN, Prabhakar AT, Mathew V, Aaron S, Alexander M. Clinical spectrum, therapeutic outcomes, and prognostic 
predictors in Sjogren's syndromeassociated neuropathy. Annals of Indian Academy of Neurology. 2017 Jul;20(3): 278.

10. Rafai MA, Boulaajaj FZ, Moutawakil F, Addali N, El Moutawakkil B, Fadel H, Hakim K, Bourezgui M, Sibai M, El Otmani H, Slassi I. Neurological manifestations revealing primitive Gougerot-Sjogren syndrome: 9 cases. Joint Bone Spine. 2009 Mar 1;76(2):13945.

11. Allen JA, Lewis RA. CIDP diagnostic pitfalls and perception of treatment benefit. Neurology. 2015 Aug 11;85(6): 498-504.

12. Mochizuki H, Kamakura K, Masaki T, Hirata A, Nakamura R, Motoyoshi K. Motor dominant neuropathy in Sjogren's syndrome: report of two cases. Internal medicine. 2002;41(2):142-6.

13. Gorson $\mathrm{KC}$, Ropper AH. Positive salivary gland biopsy, Sjögren syndrome, and neuropathy: clinical implications. Muscle \& nerve. 2003 Nov;28(5):553-60.

14. Wakasugi $\mathrm{D}$, Kato $\mathrm{T}$, Gono $\mathrm{T}$, Ito $\mathrm{E}$, Nodera H, Kawaguchi Y, Yamanaka H, Hara M. Extreme efficacy of intravenous immunoglobulin therapy for severe burning pain in a patient with small fiber neuropathy associated with primary Sjögren's syndrome. Modern rheumatology. 2009 Aug 1;19(4):437-40.

15. Levy Y, Uziel Y, Zandman G, Rotman P, Amital H, Sherer Y, Langevitz P, Goldman B, Shoenfeld Y. Response of vasculitic peripheral neuropathy to intravenous immunoglobulin. Annals of the New York Academy of Sciences. 2005 Jun;1051(1):779-86.
16. Brito-Zerón P, Ramos-Casals M. Advances in the understanding and treatment of systemic complications in Sjögren syndrome. Curr Opin Rheumatol. 2014 Jul 19.PubMed PMID: 25050925. 